Authors:

David Bramwell Jeffery (MSc. BSc (Hons); RMN): Advanced Nurse Practitioner, Birmingham and Solihull Mental Health Foundation Trust; email: david.jeffery@bsmhft.nhs.uk. Tel: 0121 301 3978, The Vibe Studio, Uffculme Learning Centre, Moseley, Birmingham, B13 8QY.

Dr. Pauline Penelope Fuller (PhD. BA. PGCE): Senior Lecturer / Award Leader Professional Doctorate in Health \& Wellbeing.

E-mail: paulinefuller@wlv.avc.uk.Tel: 01920323545 / 568220.

Faculty of Education, Health \& Wellbeing, University of Wolverhampton, Mary Seacole Building (MH), Nursery Street, Wolverhampton. WV1 1AD

\title{
Witnessing Violence: What are the experiences of psychiatric nurses?
}

\begin{abstract}
British psychiatric nurses are ten times more likely to be assaulted than general nurses. Research on this is increasing but evidence on the effects of violence on staff witnesses is lacking. Ten semi-structured interviews with witnesses were conducted. Analysis demonstrated in addition to the known effects on those who experience assault: anger, fear and guilt; they were left seeking resolution on five identified themes relating to personal and professional conflict. They were drawn towards informal forums for support, reinforcing perceptions of management as uncaring. Further research into psychiatric nurses' lived experience of debrief and support in the workplace is needed.
\end{abstract}

Background and Justification for Study

It has been identified that the occurrence of violence and aggression towards staff in UK mental health services is significant; with a direct cost to the NHS estimated at $f 69$ million per annum (National Audit Office, 2003). Recently NHS Protect (NHSP) identified that violence against health care staff accounts for 68,683 of all incidents per annum (NHSP, 2014). Physical assaults against mental healthcare staff are over 47,000 . Furthermore, it is reported that psychiatric nurses are ten times more likely to be assaulted compared to their general nurse colleagues (Parrish, 2014).

The study of violence and aggression has been established as being either notoriously scant or lacking rigour (Hinsby and Baker, 2004). Areas of investigation have primarily focused upon causation (Berkowitz, 1962, Bandura, 1975, Zillman, 1979, Lanza, 1988, Valimaki and Leino-Kilpi, 1998,), frequency (Yudofski et al, 1986, Gudjonsson, 1999, Gudjonsson et al, 2000) and management (Wright, 1999, Turnball and Patterson, 1999, Duxbury, 1999, Jeffery and Austen, 2005). The National Institute for Clinical Excellence (NICE) has called for a richer 
research base regarding the subjective viewpoint of both staff and service users (NICE, 2005).

Study into psychological and emotional effects of exposure to violence remains limited (Needham et al, 2005, Wildgoose et al, 2003, Lam, 2002, Duxbury, 2002). There is a more substantial research deficit on the impact upon those who have witnessed physical assault (Schat and Kelloway, 2000), particularly in relation to psychiatric nurses (Jeffery, 2010). It is a cause for concern that $89 \%$ of such nurses have witnessed actual or potential assault during the course of their work (Healthcare Commission, 2005). Currid (2009, p.46) posits that greater study needs to be done to establish the lived experiences of nurses exposed to violence and address data deficits in this area.

Over the past 25 years constructs have been developed that endeavour to establish meaning and formulate hypotheses in relation to those who have been a frequent witness to violent acts (Schreuder et al, 2001). Concepts such a Vicarious Trauma (VT) and Secondary Traumatic Stress (STS) are fast becoming associated as a potential side-effect in the caring professions (Collins and Long, 2003, Jenkins and Elliot, 2004), even implying that Post-Traumatic Stress Disorder (PTSD) may present in the therapist as a result of listening to the traumatic experiences of their clients (McCann and Pearlman 1990, Pearlman and Saakvitne, 1995, Figley, 1995, Figley and Stamm, 1996). While these concepts originate from psychodynamic interaction it has been suggested that VT and STS have equal relevance to those who are exposed to the physical trauma of others (Bloom and Reichert, 1998). Richter and Berger (2006) conclude that if left unchecked those who regularly witness violence or aggression may develop PTSD. Hence this may have implications for mental health practitioners and their clinical practice (Whittington and Wykes, 1994).

This study therefore aimed to redress the deficits in literature with regard to the experiences of psychiatric nurses on witnessing violence.

\section{Ethics}

The study was granted ethical approval by the lead investigator's academic institution and the Research and Development Departments at the participants' Trust. Permission to conduct the study with staff in the clinical areas was granted by the deputy director of nursing. A full participant information leaflet explaining the details of the study was sent to each participant who expressed an interest in participating as well as a right to withdraw form. All participants signed the consent to participate form and the right to withdraw element was reiterated verbally before the start of each interview. Given the sensitive nature of the topic area the investigator arranged for participants to have access to the local staff support department. Participants were informed of this via the information sheet and reminded of this arrangement pre and post interview. Information was handled in accordance with the Data Protection Act (1998) and stored on password protected and encrypted devices held by the investigator at all times. Anonymity was maintained by the use of pseudonyms and coding. 


\section{Sampling and Population}

The study focused upon 10 psychiatric nurses who work in acute mental health settings and Psychiatric Intensive Care Units (PICU) and who had witnessed an episode of physical violence in the previous six months. There is evidence that mental health nurses working in these areas are more likely to experience physical violence (Green and Robinson, 2005). The sample was drawn purposefully from members of staff who attend aggression management training within the lead investigator's mental health trust. At the beginning of each training event the course facilitator read a consistent statement from a prompt card inviting those interested in participating to make it known and they were then given an envelope. The envelopes were unmarked and contained an expression of interest form and those interested in participating handed them in as instructed. The investigator sent those selected a formal invitation to participate letter and an information sheet detailing the study. Participant characteristics can be seen in figure 1.

$\begin{array}{ll}\text { Participant } & \text { Number } \\ \text { Characteristics } & \\ \text { Male } & 5 \\ \text { Female } & 5 \\ \text { Qualified Nurses } & 6 \\ \text { Unqualified Nurses } & 4 \\ \text { Age Range } & 25-55 \\ & \text { years } \\ \text { Experience Range } & 3-35 \text { years } \\ \text { PICU Services } & 4 \\ \text { Acute Services } & 3 \\ \text { Forensic Services } & 3 \\ \end{array}$

Figure 1: Participant Characteristics

Research Design: Methodology \& Methods

The study is qualitative in design since this is appropriate to capture the subjective nature of human experience (Glaser and Strauss, 1967). The dearth of current evidence in respect of those who witness events of physical violence and its impact, lends itself to a methodology that employs Grounded Theory (GT). GT helps to explore and generate emergent thematic content in a systematic process of data collection and analysis. As such the process assists in 
the development of theoretical composites in areas of either limited study or where a new perspective is sought (Strauss and Corbin, 1998, Glaser, 2002, Maijala et al, 2003).

A one hour semi structured interview was used to obtain each participant's 'narrative' of their subjective experience as a witness to physical violence. These narratives were taped and then transcribed for coding and data analysis. The interviews were conducted at a time and place of the participant's choosing in a private and quiet room. Two pilot interviews were held to test the suitability of the interview schedule, facilitate amendments to questions and allow familiarisation with the GT methods and analysis tools. As noted by van Teijlingen and Hundley (2001) the progressive nature of qualitative data collection and analysis allows data from pilot studies to be included in the overall sample. The initial two respondents from the sample who agreed to take part were the first to be interviewed.

The study utilises constant comparative analysis of data since this method aggregates contextual meaning by formalising the development of emergent themes from textual data (Bryman, 2001). The transcribed data went through a coding process unique to Straussarian GT, that is: open coding, line by line coding, axial coding and selective coding. In keeping with qualitative inquiry researcher bias throughout the interpretive process was minimised by the use of reflexivity, triangulation of field notes and extensive theoretical memoing, as well as member checking emergent themes with participants.

Findings

Data analysis identified five major themes pertinent to study participant's (SP) lived experience of witnessing violence. These are illustrated in figure 2:

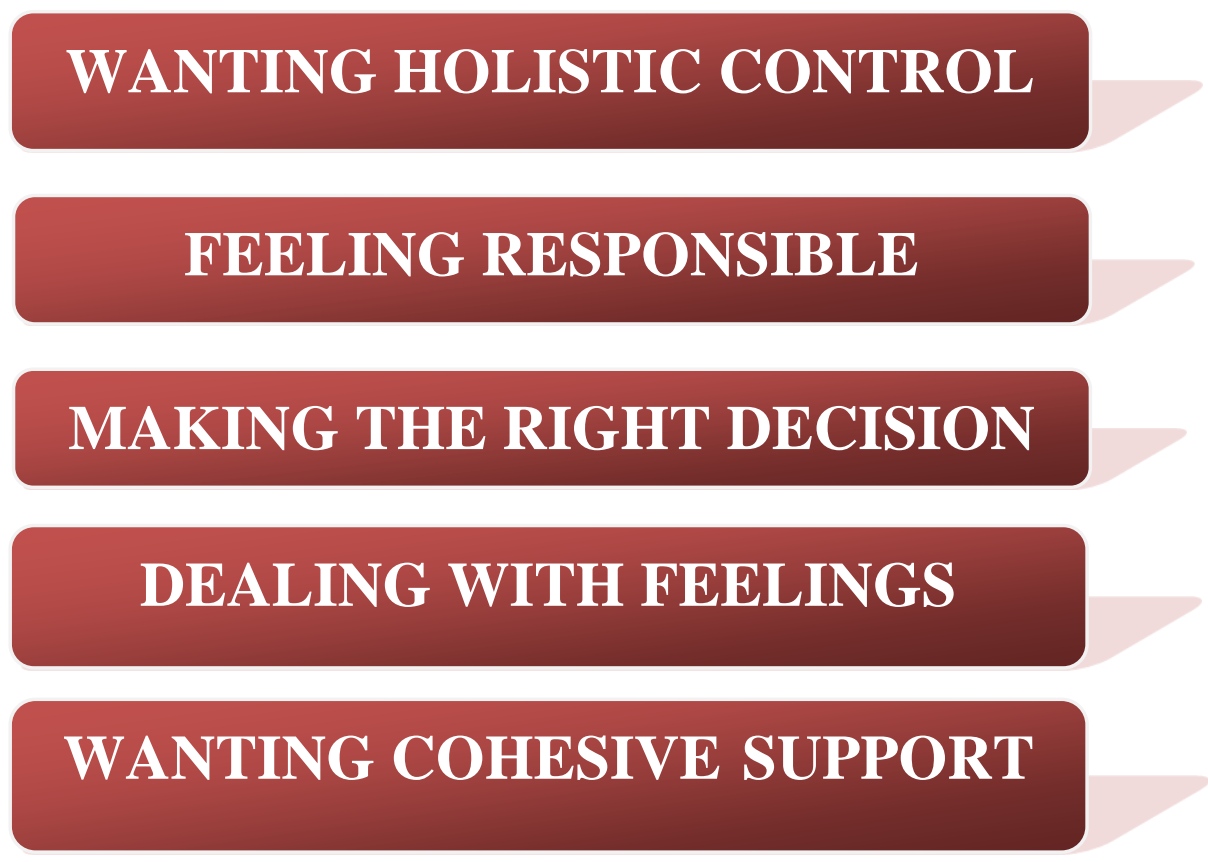

Figure 2: Five key themes of witnessing violence

Wanting Holistic Control

The theme of wanting holistic control is born from the apparent need of participants to seek appeasement in two aspects of their experience of witnessing violence: controlling the 
actual incident and their ability to exert personal control on the physical event, balanced with their professional and emotional responses. In terms of managing the actual incident the primary goal of seeking control was considered a defining element in the event. With control taking such precedence its absence from the event became a source of deep concern. Indeed, the concept of control being the benchmark for the success or failure of an incident was a focus for many participants.

The concept of a recognised process that did not go according to plan ameliorates the need for controlling the incident and the subsequent personal feelings incurred by staff when such benchmarking is perceived to be at odds with the actualities of the event. This is supported in the literature (Currid, 2009, Sequeira and Halstead, 2004).

Feeling Responsible

The theme of feeling responsible indicates how participants sought to identify the sources of on-going emotional conflict post-incident and their attempts to manage them.

Participants identified with the notion that effective co-ordination and management of an incident was reflective of assumed or actual performance.

This concept of action or inaction is ascribed to assumed or actual roles. Those who had been nurse in charge (NIC) at the time were specific in what they perceived this role to be in terms of predicting and therefore avoiding the event from occurring in the first place. This concept of the NIC being symbiotic with responsibility for the event in its entirety was given credence by participants.

The sense of helplessness when coming to the assistance of colleagues left participants feeling that they had let colleagues down in some way. This was considered on both an individual and group level. This had emotional implications in terms of what some participants felt about their responses to colleagues who had been assaulted and the amount of support they did or didn't offer. Whilst participant feelings of responsibility are evident in the narrative, being told by others that they had done a good job did not appear to be a means of resolution.

Making the Right Decision

The concept of making the right decision also required a degree of validation from peers in order for participants to reaffirm that choices made at the time were appropriate and not a source of future contention with colleagues. The decision to involve tertiary services was difficult for some participants and feeds into the need for their decision to be validated by the service they have employed for example: the police. Overall, taking action was based on minimising risk through proactive measures and in doing so was considered justifiable in the decision making process. With some participants this extended to needing to satisfy personal doubts over their actions and decisions. When this occurred even the assurances from colleagues who had been assaulted were not enough to quash the belief they had not done everything that could have been done.

\section{Dealing with Feelings}

Post incident the participants were often left with 'emotional residue', that is the feelings that remained with them after their experience of witnessing violence. How people dealt with such feelings was varied. There was parity however to the extent they were affected by the events in which they were involved.

Participants described a range of emotions and how such feelings affected them both at the time and post-incident. Guilt and anger were prominent experiences though these factors 
were not always considered in tandem. For other participants guilt was the prominent entity when they reflected on their witnessing experience and the sources of this feeling were often multiple, for example: for the service user and for the member of staff.

Reports of feeling fearful and scared during the incident featured prominently in many of the narratives. Some participants were able to put their fear into context, identifying the elements in the event that fuelled their anxieties. In some instances it was the fear of the unknown or levels of threat or risk to all parties.

The participants frequently described how shocking the event was and were able to empathise with how the event may have impacted upon service users who had witnessed it. Such factors reflect the current evidence base (Sequiera and Halstead, 2004). As identified by Deans (2004), the participants described incident regularity as a normalising factor whilst the presence of stress and anxiety was commonplace.

A sub-theme in 'dealing with feelings' was how the subsequent emotional impact affected the person who had witnessed the violent incident in terms of both professional and personal factors and the subsequent consequences for each.

Witnessing an incident of violence and its emotional influence on professional roles was clarified by participants. Staff found that managing unprofessional attitudes was a cause for concern. The presence of the outcomes of witnessing violence and the emotional implications for the therapeutic alliance with assailants after the event, had prominence in the data and is supported by current knowledge (Bimenyimana et al, 2009, Chapman et al, 2010, Chen et al, 2007). Several staff talked about how they avoided the service user in the days following the event. Avoidance behaviours were rationalised by suggesting it was motivated by concerns for the emotional well-being of the service user or the demands of clinical activity.

There was a regular perspective that, due to the level of exposure to such incidents, violence was often considered part of the job. Participant views as to the sources of such an ethos were varied. For some it was the frequency of exposure. For others it was places of work where the risks are considered inherent within the environment, for example forensic settings. Some staff felt that this was perpetuated by the readiness of nurses to accept its ubiquity.

The influence of the event on the home/work-life sequelae was evident in the narratives of several participants. This ranged from emotional intolerance of family members, internalisation or ruminating on events, and the prophylactic use of alcohol. Making contact with work to see if the unit was settled was also described as another means of easing emotional uncertainty.

Wanting Cohesive Support

Support in the aftermath of witnessing violence has significant presence in the data. The theme wanting cohesive support is divided seven sub themes:

a) Feeling that debrief is inconsistently applied, not available when needed or not available at all;

b) Feeling that support was an informal or staff driven process;

c) Feeling support processes are a device for consolidation and learning;

d) Finding the debrief process critical and impersonal;

e) Feelings of being supported and unsupported;

f) Feeling uncared for by management and the organisation;

g) Seeking alternative modes of support. 
The concept of debrief was significant in the data, especially surrounding its application, access and individual familiarity with the process. For some, debrief as a mode of support proved inconsistent or did not feature at all. The data suggests that when support was in place it was often both informal and driven by the staff involved. The support offered by immediate colleagues was also welcomed by participants; describing how they used this forum to talk through their thoughts on the event and support others. However, the use of colleagues as support was not always conducive to resolution. Some participants found that rather than address the prevalent issues it led to a counterproductive view of management that remained unchallenged.

Staff had a clear view on post incident support as not only the means of finding emotional resolution but the platform by which learning could take place. Experiences were contrary to this, when debrief and support are available, the blurring of debrief and incident review is compounded further by how the forum was managed by senior staff; with staff in some instances feeling criticised. Participants were clear in their view that the initiation of any support mechanism lay with managers. That management is considered synonymous with the instigation of support is strong in the data. Equally prevalent is the notion that if support is not considered robust enough, or is altogether absent, then this represents management and the wider organisation not caring of its staff.

The upshot of any post incident support, or lack of it, was given voice in participant' feelings on how supported they felt on reflection. Support was considered as the practical help given by others at the time. The presence of solid leadership and its assumed links to support also featured in the data. Inconsistencies in the supportive experience had participants seeking alternative forums in order to deal with the emotional consequences of witnessing violence. Some used their immediate family for reassurance as a matter of course with inconsistent outcomes. In some instances support outside the place of work, for example psychology services, was sought with positive outcomes.

Discussion: Seeking Resolution to Personal and Professional Conflict Given that participants emerged from the experience with such a sense of emotional destabilisation, it is perhaps unsurprising they were left needing to explain and rationalise their choices and actions whilst wanting the means to share and manage their feelings. Ultimately the inclusivity of both of these needs can be considered as the vehicle by which those who have witnessed violence seek an overall resolution of conflicting emotions post incident and the consequences of this on their practice. It is argued that in the wake of witnessing a violent incident staff feel the need to rationalise and explain the choices that they made and the actions that they took at the time. This dynamic is illustrated in the theoretical model in figure 3. 


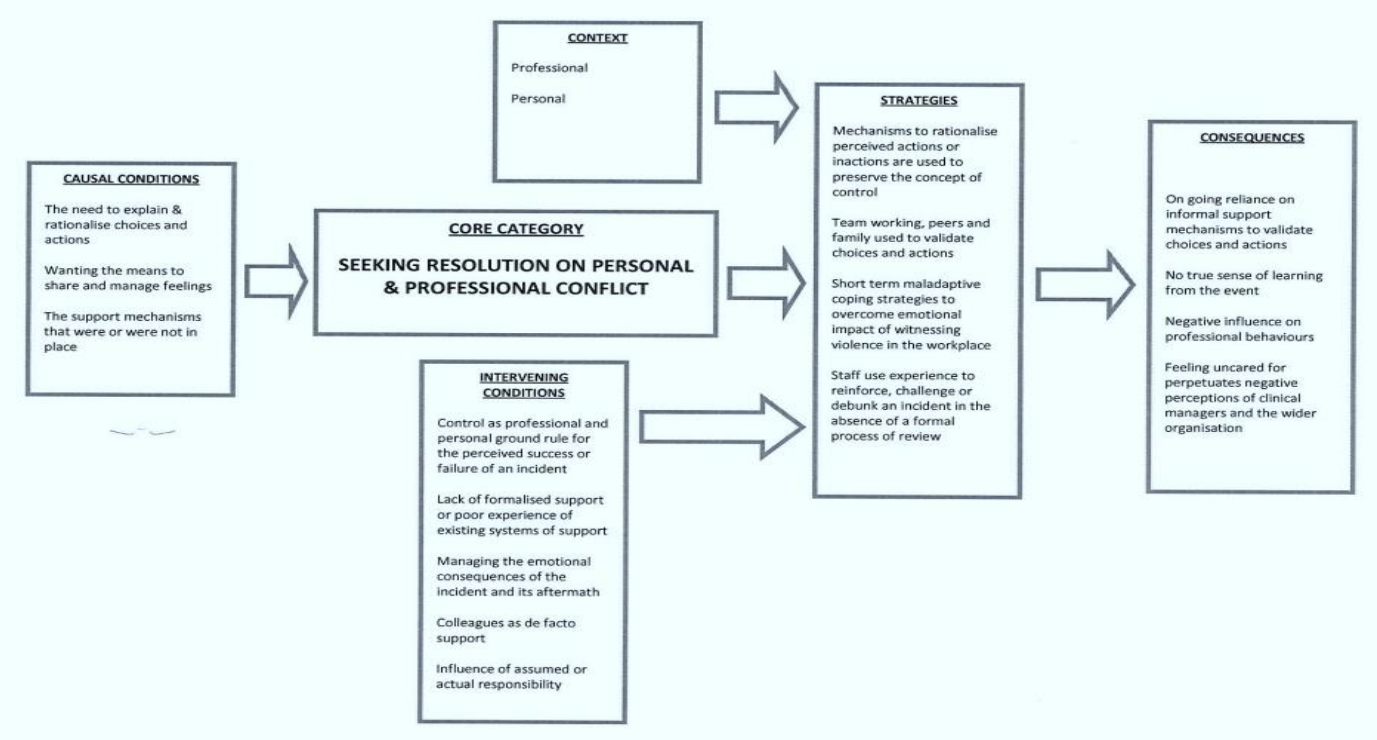

Figure 3: Seeking Resolution on Personal and Professional Conflict: Theoretical Model

Whilst these strategies appear to provide solace and satisfaction it is posited they often lead to subjective views of the event and maladaptive coping strategies. These elements were unwittingly perpetuated by having to rely on the informal support of colleagues because access to other processes was either absent or lacking immediacy.

Strengths and Limitations

The small sample size is not commensurate with a full GT study but saturation has been found to take place with a minimum of ten participants (Thomson, 2011, p. 46). Whilst Sandelowski (2007, p. 180) suggests merely increasing sample size is not a guarantee of a strengthened qualitative study it is argued that the limited evidence base in the subject area warrants more data in order to give the findings a broader meaning. In view of this it is suggested that a larger study is developed to further garner the experiences of staff. Another sampling issue is a disproportionate representation of qualified to unqualified staff which needs to be considered when addressing findings such as responsibilities and assumed control.

One cannot consider interviews as a method of data collection without acknowledging the impact of recall-bias and the potential emotive nature of the subject matter and the impact that the researcher has on the interpersonal dynamics of an interview cannot be overstated (Turner, 2010). Nevertheless a primary strength is that the study is one the first of its kind and gives some insights into participants' experiences of witnessing violence. In this the findings become a catalyst for further studies such as:

1. The lived experiences of debrief and support following an incident of violence.

2. Psychiatric nurses' perceptions of the assumed or actual role of the nurse in charge during an incident of high risk.

3. Psychiatric nurses' perspectives of control in a clinical setting.

4. How psychiatric nurses support each other during and after a violent incident. 
Implications for Policy and Practice

Noteworthy implications related to current national policy on staff support and its uptake in clinical services. Several key documents with a remit for managing aggression and violence in mental healthcare settings feature the importance of supporting staff in its aftermath. This study strongly underpins the current evidence base that has found staff access to debrief and support overwhelmingly scant or a fundamentally negative experience (Bimenyimana et al, 2009, Chapman et al, 2010, Chen et al, 2007, Kindy, Petersen and Parkhurst, 2005, Deans, 2004). Definitive guidance as to how debrief \& support should be implemented at service level remains lacking. It is hoped that the findings of this study gives voice to those psychiatric nurses who are working with and witnessing violence on a regular basis and thus stimulates debate on how national and local policy can be improved in real terms.

\section{References}

Bandura, A. (1975) Social Learning and Personality Development. NJ: Holt, Rinehart and Wilson Inc.

Berkowitz, L. (1962) Aggression: a Social Psychological Analysis. San-Francisco: McGraw-Hill.

Bimenyimana, E., Poggenpoel, M., Myburgh, C. et al. (2009) The lived experience by psychiatric nurses of aggression and violence from patients in a Gauteng psychiatric institution. Curationis 32(3), pp.4-13.

Bloom, S.L. \& Reichert, M. (1998) Bearing Witness: Violence and Collective Responsibility. NY: The Haworth Press Inc.

Bryman, A. (2001) Social Research Methods. Oxford: Oxford University Press.

Chapman, R., Perry, L., Styles, I. et al. (2009) Consequences of workplace violence directed at nurses. British Journal of Nursing. 18(20), pp.1256-1261.

Chen, W.C., Wang, J.D., Lew-Ting, C.Y., et al. (2007) Workplace violence on workers caring for long-term institutionalized schizophrenic patients in Taiwan. Journal of Occupational Health. 49, pp. 311-316.

Collins, S. \& Long, A. (2003) Too tired to care? The psychological effects of working with trauma. Journal of Psychiatric and Mental Health Nursing. 10, pp.17-27 London: Blackwell Publishing.

Currid, T. (2009) Experiences of stress among nurses in acute mental health settings. Nursing Standard. 23(44), pp. 40-46.

Deans, C. (2004) Who cares for nurses? The lived experience of workplace aggression. Collegian Journal. 11(1), pp.32-36. 
Duxbury, J. (1999) An exploratory account of registered nurses' experience of patient aggression in both mental health and general nursing settings. Journal of Psychiatric and Mental Health Nursing. 6, pp.107-114.

Duxbury, J. (2002) An evaluation of staff and patient's views of and strategies employed to manage patient aggression and violence on one mental health unit. Journal of Psychiatric and Mental Health Nursing 9, pp.325-337.

Figley, C.R. (Editor) (1995) Compassion Fatigue: Coping with Secondary Traumatic Stress Disorder in Those Who Treat the Traumatised. New York: Brunner/Mazel.

Figley, C. R. \& Stamm, B. H. (1996) Psychometric review of compassion fatigue self test' in Stamm, B.H. (Editor) (1996) Measurement of Stress, Trauma and Adaptation. pp.65-73, Lutherville, Maryland: Sidran Press.

Glaser, B.G. (2002) Grounded theory and gender relevance. Health Care for Women International 23 (8), pp.786-793.

Glaser, B.G. \& Strauss, A.L. (1967) The Discovery of Grounded Theory: Strategies for Qualitative Research. Chicago: Aldine Publishers.

Green, B. \& Robinson, L. (2005) Reducing violence in a forensic mental health unit: a seven year study. Mental Health Practice. 9(4), pp.40-44.

Gudjonsson, G. (1999) Violent incidents on a secure unit over a 17 year period. Journal of Forensic Psychiatry 10, pp.249-263.

Gudjonsson, G., Rabe-Hesketh, S. \& Wilson, C. (2000) Violent incidents on a medium secure unit: the target of assault and the management of incidents. Journal of Forensic Psychiatry. 11, pp.105-118.

Healthcare Commission (2005) The National Audit of Violence (2003-2005) Final Report. London: Royal College of Psychiatrists Research Unit.

HMSO (1998) The Data Protection Act (1998) London, The Stationary Office.

Hinsby, K. \& Baker, M. (2004) Patient and nurse accounts of violent incidents in a medium secure unit. Journal of Psychiatric and Mental Health Nursing. 11, pp.341-347.

Jeffery, D. (2010) A literature review on workplace violence in mental health services. Journal of Health and Social Care Improvement. [online] October 2010 Issue [accessed April 5th 2011] Available from http://www.wlv.ac.uk/default.aspx?page=25398

Jeffery, D. \& Austen, S. (2005) Adapting de-escalation techniques with deaf service users. Nursing Standard. 19(49), pp.41-47. 
Jenkins, R. \& Elliot, P. (2004) Stressors, burnout and social support: nurses in acute mental health settings. Journal of Advanced Nursing 48(6), pp.622-31.

Kindy, D., Petersen, S. \& Parkhurst, D. (2005) Perilous work: nurses' experiences in psychiatric units with high risks of assault. Archives of Psychiatric Nursing. 19(4), pp. 169175.

Lam, L.T. (2002) Aggression exposure and mental health among nurses. Australian Journal for the Advancement of Mental Health. 1(2), pp.1-12.

Lanza, M.L. (1988) Factors relevant to patient assault. Issues in Mental Health Nursing 9, pp.239-257.

Maijala, H., Paavilainen, E. \& Ast-edt-Kurki, P. (2003) The use of grounded theory to study interaction. Nurse Researcher. 11(2), pp.40-57.

Martin, T. \& Daffern, M. (2006) Clinician perceptions of personal safety and confidence to manage inpatient aggression in a forensic psychiatric setting. Psychiatric and Mental Health Nursing. 13(1), pp. 90-99.

McCann, L. \& Pearlman, L.A. (1990) Vicarious traumatisation: a framework for understanding the psychological effects of working with victims. Journal of Traumatic Stress. 3(1), pp.131-149.

National Audit Office (2003) A Safer Place to Work: Improving the management of health and safety Risks to Staff in NHS Trusts. London: NAO.

National Institute for Clinical Excellence (2005) The Short-term Management of Disturbed/Violent Behaviour in In-patient Psychiatric Settings and Emergency Departments: Full Report. London: The Stationary Office.

Needham, I., Abderhalden, C., Halfens, R.J.G et al. (2005) Non-somatic effects of patient aggression on nurses: a systematic review. Journal of Advanced Nursing. 49(3), pp.283-296.

NHS Protect (2014) Report on Number of Physical Assaults on NHS Staff 2013/2014 [Online] PDF. London: NHSBA. [Accessed December 2014] Available at:

http://www.nhsbsa.nhs.uk/Documents/SecurityManagement/Reported_Physical_Assaults_ 2013-14.pdf

Parrish, C. (2014) A report that hits home. Mental Health Practice. 18(4), pp.5-6.

Pearlman, L.A. \& Saakvitne, K.W. (1995) Trauma and the Therapist: Countertransference and Vicarious Traumatisation in Psychotherapy with Incest Survivors. London: W.W. Norton.

Polit, D.F. \& Beck, C.T. (2006) Essentials of Nursing Research: Methods, Appraisal, and Utilization. $6^{\text {th }}$ ed. Philadelphia, Baltimore, New York, London, Buenos Aires, Hong Kong, Sydney, Tokyo: Lippincott Williams \& Wilkins. 
Richter, D. \& Berger, K. (2006) Post traumatic stress disorder following patient assaults among staff members of mental health hospitals: a prospective longitudinal study. $B M C$ Psychiatry. 6(12), pp.2-12.

Schat, A. \& Kelloway, K. (2000) Effects of perceived control on the outcomes of workplace aggression and violence. Journal of Occupational Health Psychology. 5. pp. 386-402.

Sequeira, H. \& Halstead, S. (2004) The psychological effects on nursing staff of administering physical restraint in a secure psychiatric hospital: "When I go home, it's then that I think about it". The British Journal of Forensic Practice. 6(1), pp.3-15.

Schreuder, B.J.N., Igreja, V., van Dijk J. et al. (2001) Intrusive re-experiencing of chronic strife or war. Advances in Psychiatric Treatment. 7, pp.102-108.

Strauss, A. \& Corbin, J. (1998) Basics of Qualitative Research: Techniques and Procedures for Developing Grounded Theory $2^{\text {nd }}$ Edition. London: Sage Publications.

Teijlingen van, E.R. \& Hundley, V. (2001) The importance of pilot studies. Social Research Update [online] Issue 35 [accessed 7th April 2011] Available from:

<http://sru.soc.surrey.ac.uk/SRU35.html>

Turnball, J. \& Patterson, B. (1999) Aggression and Violence. London: Macmillan.

Whittington, R. \& Wykes, T. (1994) Going in strong: confrontative coping by staff following assault by a patient. Journal of Forensic Psychiatry. 5, pp.609-14.

Wildgoose, J., Briscoe, M. \& Lloyd, K. (2003) Psychological and emotional problems in staff following assaults by patients. Psychiatric Bulletin. 27, pp.295-297.

Wright, S. (1999) Physical restraint in the management of violence and aggression in inpatient settings: a review of issues. Journal of Mental Health. 8, pp.459-472.

Valimaki, M. \& Leino-Kilipi, H. (1998) Preconditions for and consequences of selfdetermination: the psychiatric patient's point of view. Journal of Advanced Nursing 27, pp.204-212.

Yudofsky, S.C., Silver, J.M., Jackson, W., et al. (1986) The overt aggression scale for the objective rating of verbal and physical aggression. American Journal of Psychiatry. 143, pp.35-39.

Zillman, D. (1979) Hostility and Aggression Hillsdale. NJ: Erlbaum Publishing. 